\title{
Improving the clinical ability and quality of endocrinology department with diagnosis-related groups tool
}

\author{
Sheng Ding ${ }^{1,2 \#}$, Xiaowan Jiang ${ }^{1,2 \#}$, Yuming Zheng ${ }^{2,3}$, Tao Feng ${ }^{2,4}$, Hong Mao ${ }^{1,2}$, Zhi Chen ${ }^{2,3}$, Wei Cai ${ }^{2,5}$, \\ Zhongjing Wang ${ }^{1,2}$
}

${ }^{1}$ Department of Endocrinology, The Central Hospital of Wuhan, Tongji Medical College, Huazhong University of Science and Technology, Wuhan, China; ${ }^{2}$ Key Laboratory for Molecular Diagnosis of Hubei Province, The Central Hospital of Wuhan, Tongji Medical College, Huazhong University of Science and Technology, Wuhan, China; ${ }^{3}$ Department of Physical Examination, The Central Hospital of Wuhan, Tongji Medical College, Huazhong University of Science and Technology, Wuhan, China; ${ }^{4}$ Medical Department, The Central Hospital of Wuhan, Tongji Medical College, Huazhong University of Science and Technology, Wuhan, China; ${ }^{5}$ Administration Office, The Central Hospital of Wuhan, Tongji Medical College, Huazhong University of Science and Technology, Wuhan, China

Contributions: (I) Conception and design: S Ding, W Cai, Z Wang; (II) Administrative support: W Cai, T Feng, H Mao; (III) Provision of study materials or patients: S Ding, Z Wang; (IV) Collection and assembly of data: X Jiang, Z Chen; (V) Data analysis and interpretation: S Ding, Y Zheng; (VI) Manuscript writing: All authors; (VII) Final approval of manuscript: All authors.

\#These authors contributed equally to this work.

Correspondence to: Zhongjing Wang. Department of Endocrinology, The Central Hospital of Wuhan, Tongji Medical College, Huazhong University of Science and Technology, Wuhan 430014, China. Email: doctorwangzj@163.com; Wei Cai. Administration Office, The Central Hospital of Wuhan, Tongji Medical College, Huazhong University of Science and Technology, Wuhan 430014, China. Email: 76308501@qq.com; Zhi Chen. Department of Physical Examination, The Central Hospital of Wuhan, Tongji Medical College, Huazhong University of Science and Technology, Wuhan 430014, China. Email: $1218159 @ q q . c o m$.

Background: To evaluate the use of the diagnosis-related groups (DRGs) tool to promote the diagnosis/ treatment ability and quality of the endocrinology department under the new policy of grouping paymentrelated to disease diagnosis.

Methods: We compared the income structure of the endocrinology department in a 3a general hospital between the first half of 2019 and the same period in 2021. We also observed the changes in cost efficiency indexes (CEIs), time efficiency indexes (TEIs), case-mix index (CMI), number of DRGs, risk weight (RW) proportion, and surgery number in the inpatient department. Furthermore, the distribution of inpatients with diabetes of the whole hospital and the improvement of treatment efficiency indexes of the sub-specialty department were analyzed.

Results: In the first half of 2021, compared with the same period of 2019, the total revenue of the endocrinology department decreased by $20.05 \%$, the average hospitalization cost decreased by $11.72 \%$, the CEI decreased from 1.31 to 1.06 , and the TEI decreased from 0.74 to 0.64 . Additionally, the number of DRGs increased from 162 to 176 , the average CMI value increased from 0.80 to 0.84 , and the proportion of RW 1-5 cases increased. Moreover, the number of surgical cases increased by $60.50 \%$, minimally invasive surgery increased by $53.54 \%$, grade 4 surgery increased by $66.67 \%$, and the proportion of entering the clinical pathway increased from $77.76 \%$ to $86.64 \%$. From May to August, 2021, the admission rate of endocrinology sub-specialty increased significantly, the number of DRGs showed an increasing trend, and the CEI and TEI decreased significantly. In the first half of 2021, inpatients with diabetes in the departments of rehabilitation, neurology, nephropathy, ophthalmology, and general administration accounted for 21.99-38.54\%.

Conclusions: The DRGs tool can be used to improve the clinical diagnosis and treatment ability of the endocrinology department, as well as optimize the CEI, TEI, CMI, and RW values. It is an effective way to promote the development of the endocrinology department under the new DRGs payment policy, carry out blood glucose management in the hospital, build endocrinology sub-specialties, and improve surgical and operation capacity. 
Keywords: Diagnosis-related groups (DRGs); diabetes mellitus (DM); case-mix index (CMI); endocrinology

Submitted Dec 07, 2021. Accepted for publication Feb 14, 2022.

doi: $10.21037 /$ atm-22-147

View this article at: https://dx.doi.org/10.21037/atm-22-147

\section{Introduction}

In recent years, performance evaluation based on diagnosisrelated groups (DRGs) has been applied in medical institutions at home and abroad, and some successful experience has been obtained (1-5). DRGs were established to standardly measure severity of illness, assessment of treatment difficulty, and resource intensity. In May 2019, China selected 30 cities as the first batch of DRG payment pilot cities, and put forward the DRG payment action guide to 'ensure simulation operation in 2020, and start actual payment in 2021' (6). One fourth of patients with diabetes mellitus (DM) over the world live in China, but the effect of DRGs payment system on the quality of medical care for inpatients of Endocrinology department is still not clear. The case-mix index (CMI) value of common diseases in endocrinology department (such as diabetes, thyroid diseases, etc.) is low, and the new policy of payment according to DRGs provides both challenges and opportunities for the development of the endocrinology department. The endocrinology department adjusted its specialty development strategy, carried out blood glucose management in the hospital and improved surgical capacity in 2021 according to the new DRGs policy. This study aims to analyze the adjustment effect and explore how to use DRG tools to improve the diagnosis/treatment ability and quality of the endocrinology department.

\section{Methods}

\section{Data sources}

Data on clinical business revenue and quality of care were included in the study, as well as data on patient distribution and the DRG disbursement ratio in the endocrinology department of the Central Hospital of Wuhan from January to June 2019 and January to August 2021. According to the China Healthcare Security DRG (CHS-DRG) $(7,8)$, data were extracted from the first page of medical records with China National DRG (CN-DRG) as the grouping device, and data were analyzed using a DRG inpatient medical service detection and analysis system provided by a software company (Diaolong Data Technology Co., Ltd., Wuhan, China). The first page of the medical records adopts an International Classification of Diseases (ICD) code National Clinical Edition: the diagnostic code is ICD-10 disease code (National Clinical Edition), and the operation code is ICD-9-CM-3 surgical operation code (National Clinical Edition 1.2).

\section{Evaluation index}

Evaluation Index System was used to assess the quality of endocrinology department. According to the Evaluation Index System of Specialized Clinical Ability (9), clinical ability was evaluated in terms of the three aspects of clinical disease diagnosis and treatment ability, clinical operation ability, and clinical work efficiency. The diagnosis and treatment ability of clinical diseases involves the following: (I) total number of patients: number of discharged patients; (II) disease coverage: number of DRG groups; (III) difficulty of diagnosis and treatment: risk weight (RW), CMI; and (IV) proportion of specialized diseases: DRG enrolment rate and proportion of entry clinical pathway. The clinical operation ability comprises the following: (I) surgery: number and proportion; and (II) high-level surgeries: number and proportion. The clinical work efficiency takes into account the following: (I) time: average length of stay, time efficiency index (TEI); and (II) cost: average hospital cost, cost efficiency index (CEI).

CMI represents the average technical difficulty level of cases in each discipline. The number of DRGs represents the type and range of treatment cases covered. The TEI represents the time spent treating the same kind of disease, and the CEI represents the cost of treating the same kind of disease. The CEI is derived from the standardized transformation of hospitalization expenses through DRGs. We used the following calculation method: calculate the ratio of the average cost of specific DRGs in our hospital to the average cost of specific DRGs in China. A similar calculation method was used for the TEI $(1-3,10)$.

Common surgeries and operations in the endocrinology department include vascular intervention for adrenal vein 
Table 1 Comparison of clinical income structure of endocrinology department before and after DRGs payment implementation

\begin{tabular}{|c|c|c|c|c|c|}
\hline Income structure & 2019 first half & 2021 first half & Percentage change (\%) & $\chi^{2}$ value & $P$ value \\
\hline Medicine cost (\%) & 38.27 & 31.58 & -17.47 & 104.088 & 0.000 \\
\hline Material cost (\%) & 6.25 & 6.79 & 8.64 & & \\
\hline Examination cost (\%) & 32.58 & 34.88 & 7.06 & & \\
\hline Other costs (\%) & 0.33 & 0.36 & 9.09 & & \\
\hline
\end{tabular}

DRGs, diagnosis-related groups.

sampling (AVS), femoral artery puncture for arteriography of lower limbs, and endovascular intervention for diabetic lower limb artery lesions. Endovascular interventional therapy (endovascular angioplasty, endovascular plaque resection, stent implantation, etc.) for arterial diseases of lower extremities is a class IV surgery (11-13). Other common operations include debridement of diabetic foot ulcers, closed negative pressure drainage of diabetic wounds, and treatment of chronic diabetic wounds with platelet-rich gel $(13,14)$.

\section{Study methods}

Total income structure, hospitalization cost, and time efficiency were compared between the first half of 2019 and 2021, and changes in the CMI, number of DRGs, proportion of RW, number of surgical cases, and proportion of cases entering the clinical pathway were observed. We also analyzed the changes in treatment conditions and efficiency indexes of secretory department by sub-specialty from January to August 2021. The distribution departments of inpatients with diabetes in the first half of 2021 were analyzed, and the blood glucose management departments were selected according to the DRG payment ratio.

\section{Statistical analysis}

Statistical analysis was performed using the SPSS22.0 software package (IBM Corp., Armonk, NY, USA). Categorical variables were expressed as counts and percentages (\%) and compared using the $\chi^{2}$ test or Fisher exact test. The Mann-Whitney $U$ test was used to compare two independent samples, and the corresponding $Z$ values are shown. A value of $\mathrm{P}<0.05$ (bilateral) was considered statistically significant.

\section{Results}

Comparison of the clinical income structure of the endocrinology department before and after DRGs payment implementation

From January to June 2021, the total revenue of the endocrinology department decreased by $20.05 \%$ compared with the same period of 2019, but the revenue structure was significantly optimized $(\mathrm{P}=0.000)$. Also, the proportion of drugs decreased by $17.47 \%$, while the proportion of consumables, examination fees, and medical income increased slightly (Table 1).

\section{Clinical competence evaluation of endocrinology specialty before and after DRGs payment implementation}

\section{Diagnosis and treatment ability of clinical diseases}

Compared with the same period in 2019, the number of discharged patients in the endocrinology department decreased by $8.86 \%$ in the first half of 2021 , and the total weight value decreased by $5.42 \%$ (4,094.72 vs. 4,329.26). However, the number of DRGs increased from 162 to 176 , and the average $\mathrm{CMI}$ value significantly increased from 0.80 to $0.84(\mathrm{P}=0.041)$. The proportion of $\mathrm{RW}<1$ decreased from $97.42 \%$ to $96.29 \%$, RW $1-2$ increased from $1.56 \%$ to $2.73 \%$, RW $2-5$ increased from $0.57 \%$ to $0.72 \%$, and the proportion of cases with high RW increased markedly $(\mathrm{P}=0.000)$. Furthermore, the proportion of entering the clinical pathway also increased notably $(\mathrm{P}=0.000)$ (Table 2$)$. There were no low-risk deaths during the study period.

\section{Clinical surgical and operation ability}

In the first half of 2021, compared with the same period in 2019 , the number of endocrinology surgeries increased by $60.50 \%$, minimally invasive surgeries increased by $53.54 \%$, 
Table 2 Clinical competence evaluation of endocrinology specialty before and after DRGs paid implementation

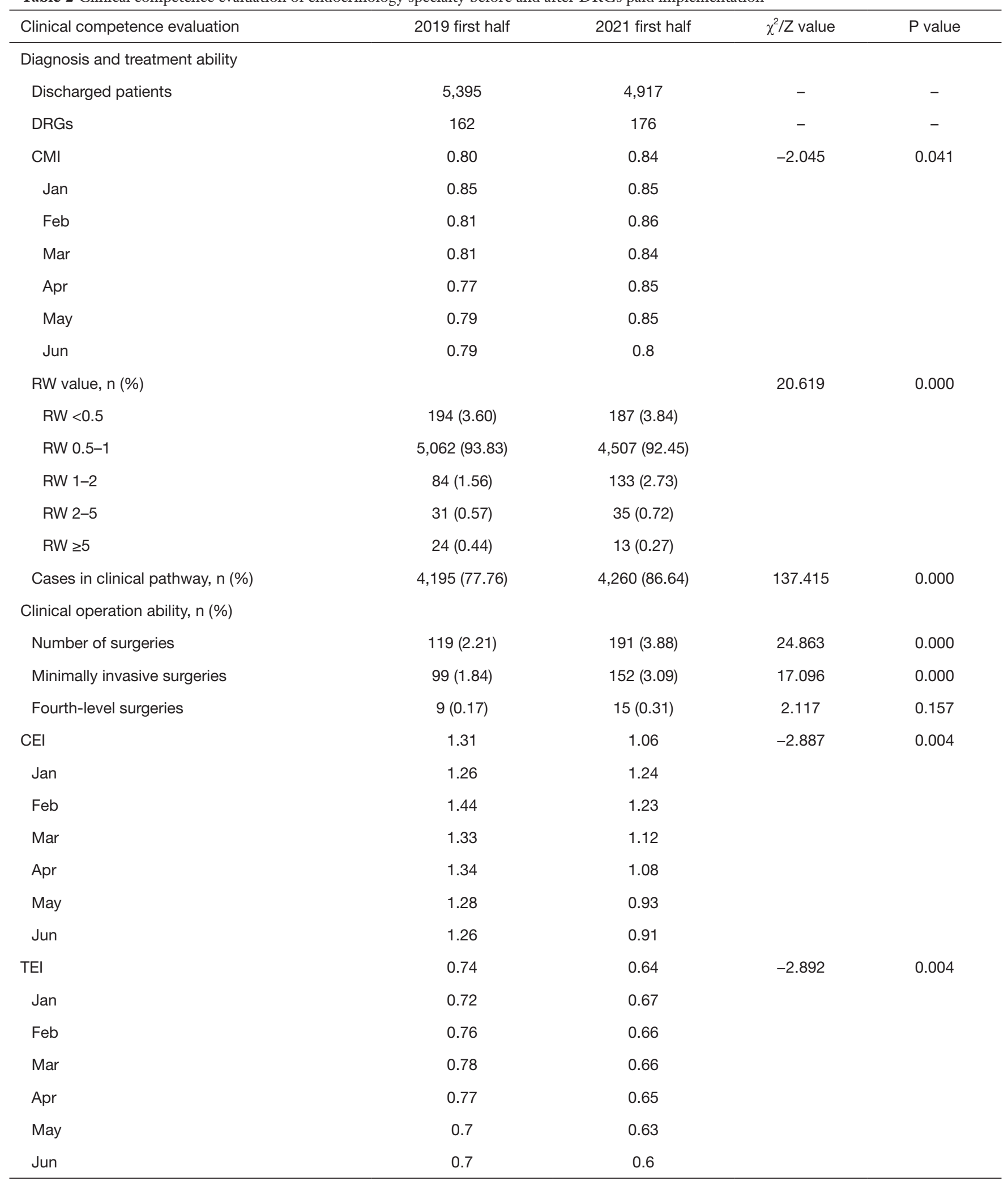

DRGs, diagnosis-related groups; CMI, case-mix index; RW, risk weight; CEl, cost efficiency index; TEl, time efficiency index. 


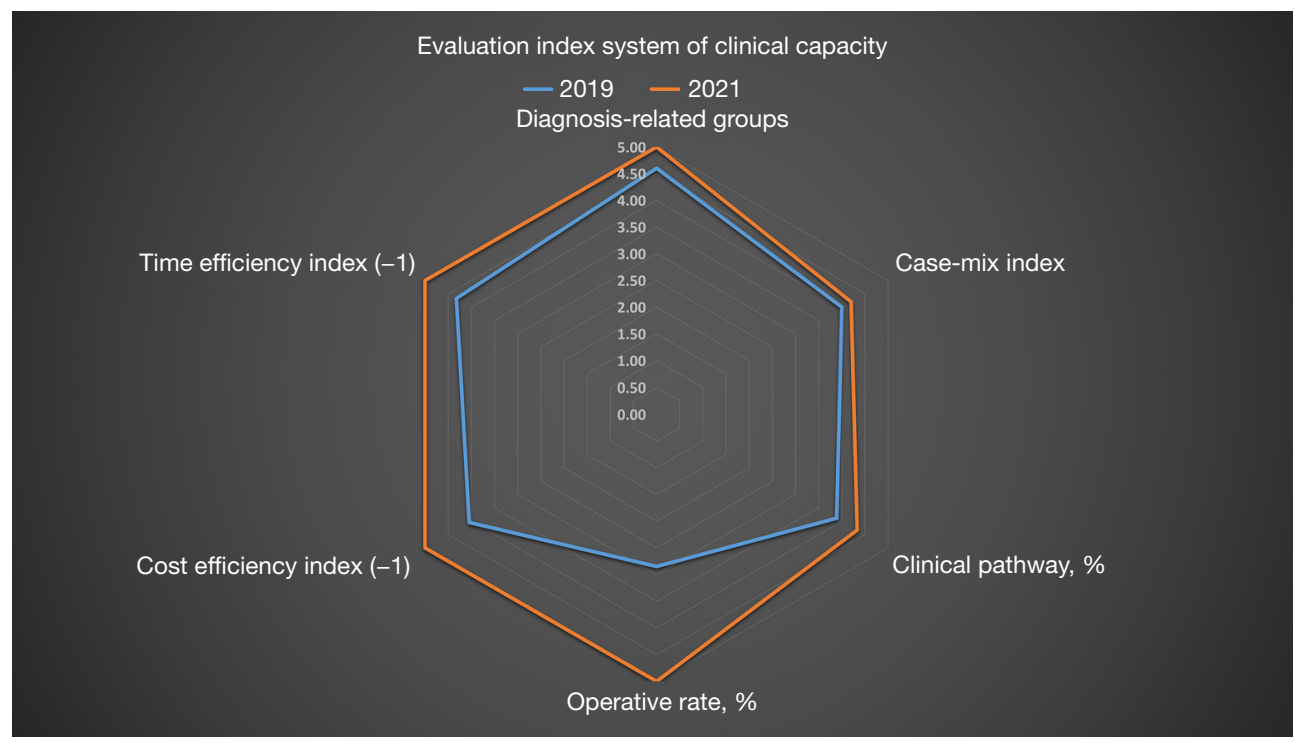

Figure 1 Evaluation index system of clinical capacity.

and fourth-level surgeries increased by $66.67 \%$. Moreover, the proportion of total surgeries and minimally invasive surgeries increased significantly $(\mathrm{P}=0.000)$.

\section{Clinical work efficiency}

In the first half of 2021, compared with the same period in 2019, the average hospitalization cost of inpatients in endocrinology department decreased by $11.72 \%(8,678.67$ $v s$. 9,830.43 Yuan), the proportion of inpatient drug costs decreased by $11.37 \%$ ( $11.07 \%$ vs. $12.49 \%$ ), and the average length of stay was shortened by $6.18 \%$ (6.38 vs. 6.80 days). Both the CEI and TEI decreased significantly $(\mathrm{P}=0.004)$ (Table 2).

The parameters of clinical service capacity in the endocrinology department in the first half of 2021 were better than those in the first half of 2019 (Figure 1).

\section{Use DRGs tool to promote the construction of endocrinology sub-specialty}

In May 2021, the endocrinology department began centralized treatment for patients with sub-specialty diseases. In addition to the special area for diabetes and complications, the department also established three non-diabetic sub-specialties, namely, the special area for pituitary, adrenal, and gonadal diseases, the special area for thyroid diseases, and the special area for metabolic diseases. The admission rate of patients with non-diabetic sub-specialty diseases in the endocrinology department from May to August 2021 was significantly higher than that of patients with non-diabetic sub-specialty diseases from January to April ( $\mathrm{P}=0.020)$ (Figure 2). The number of DRG groups showed an increasing trend, and the CEI and TEI decreased significantly (Table 3).

\section{The DRGs tool was used to select the priority blood glucose management departments of the whole hospital}

\section{Distribution of inpatients with diabetes}

In the first half of 2021, there were 15,123 diabetic patients in the hospital, of which $71.58 \%(10,825 / 15,123)$ were hospitalized in a non-endocrinology department. Nonendocrinology departments where diabetes patients accounted for more than $20 \%$ of the inpatients included the rehabilitation, neurology, nephropathy, ophthalmology, and general departments. Diabetes accounted for $87.41 \%$ of inpatients in the endocrinology department (Table 4).

DRGs payment and the development of blood glucose management in the hospital

In the first half of 2021, the medical insurance allocation ratio of the general, ophthalmology, nephrology, neurology, and rehabilitation departments were greater than $100 \%$ (Table 4). During the same period, the allocation ratio of the endocrinology department was $88.06 \%$, and the allocation ratio of the endocrinology popular science common diseases 


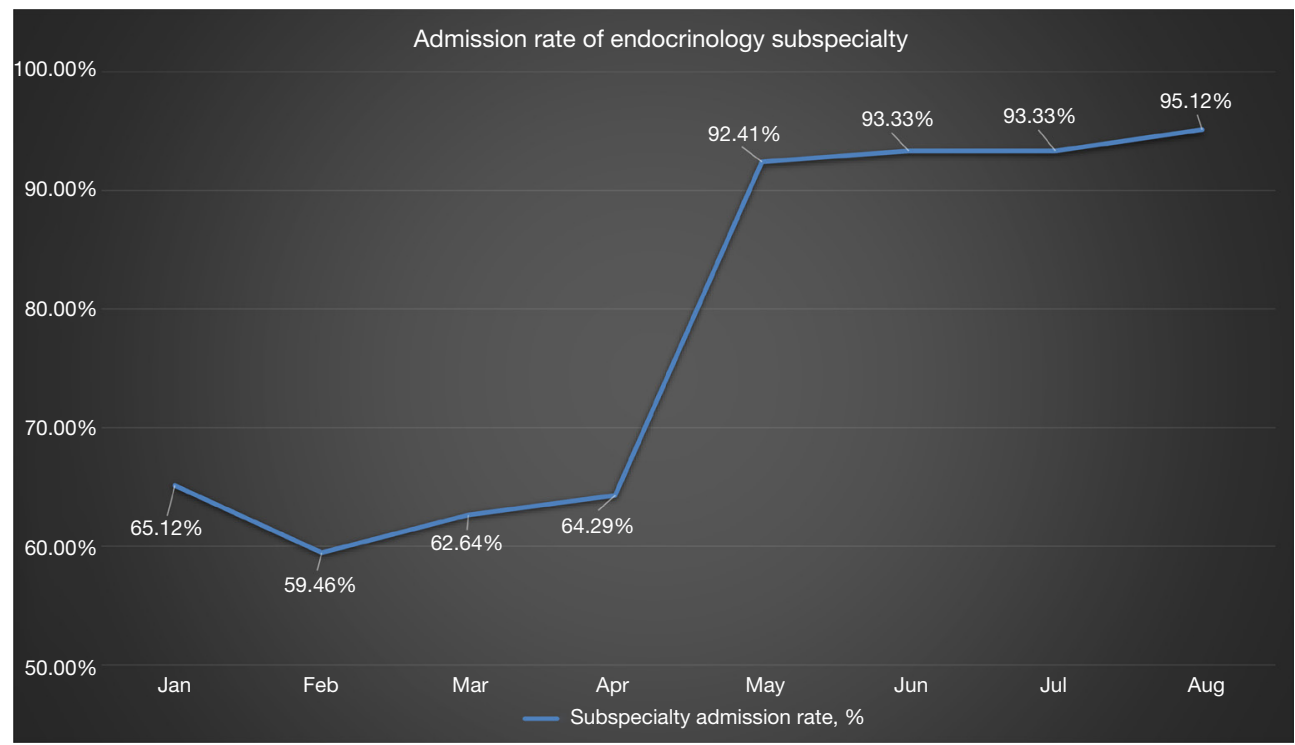

Figure 2 Endocrinology sub-specialty admission rate trend.

Table 3 Evaluation of the efficacy of endocrinology sub-specialty construction with the DRGs tool

\begin{tabular}{|c|c|c|c|c|c|c|}
\hline Month & Case in DRGs & DM cases $(\%)$ & Other sub-specialty patients (\%) & DRGs & TEl & CEI \\
\hline \multicolumn{7}{|c|}{ Before using endocrinology sub-specialty admission rule } \\
\hline Jan & 534 & $91.95(491 / 534)$ & $65.12(28 / 43)$ & 67 & 0.67 & 1.24 \\
\hline Feb & 400 & $90.75(363 / 400)$ & $59.46(22 / 37)$ & 64 & 0.66 & 1.23 \\
\hline Mar & 1,047 & $91.31(956 / 1,047)$ & $62.64(57 / 91)$ & 80 & 0.66 & 1.12 \\
\hline \multicolumn{7}{|c|}{ After using endocrinology sub-specialty admission rule } \\
\hline May & 952 & $91.70(873 / 952)$ & $92.41(73 / 79)$ & 76 & 0.63 & 0.93 \\
\hline Jun & 900 & $90.00(810 / 900)$ & $93.33(84 / 90)$ & 83 & 0.60 & 0.91 \\
\hline Jul & 799 & $90.61(724 / 799)$ & $93.33(70 / 75)$ & 77 & 0.60 & 0.90 \\
\hline$P$ value & - & 0.248 & 0.020 & 0.468 & 0.019 & 0.021 \\
\hline
\end{tabular}

DRGs, diagnosis-related groups; DM, diabetes mellitus; TEI, time efficiency index; CEI, cost efficiency index.

area $(98.94 \%$ vs. $82.00 \% ; \mathrm{P}=0.000)$. The allocation ratio of the intensive care unit $(57.90 \%$ vs. $41.10 \% ; \mathrm{P}=0.000)$ in the second quarter was significantly higher than that in the first quarter. According to the distribution of diabetes patients and DRGs payment balance, the blood glucose management of the hospital was started in July 2021, and the general, ophthalmology, nephropathy, neurology, and rehabilitation departments were included in the first batch of cross-department blood glucose management cooperation departments.

\section{Discussion}

In 2019, China started pilot testing paying for medical insurance based on DRGs in some regions $(6,7)$. The basic starting point of DRGs for the medical expense payment 
Table 4 DRGs payment and the development of blood glucose management in the hospital in the first half of 2021

\begin{tabular}{|c|c|c|c|c|c|c|}
\hline Departments & $\begin{array}{l}\text { Endocrinology } \\
\text { department }\end{array}$ & $\begin{array}{c}\text { General } \\
\text { department }\end{array}$ & $\begin{array}{l}\text { Ophthalmology } \\
\text { department }\end{array}$ & $\begin{array}{l}\text { Nephropathy } \\
\text { department }\end{array}$ & $\begin{array}{l}\text { Neurology } \\
\text { department }\end{array}$ & $\begin{array}{c}\text { Rehabilitation } \\
\text { department }\end{array}$ \\
\hline DM cases & 4,298 & 765 & 471 & 700 & 1,273 & 248 \\
\hline DM cases ratio (\%) & $\begin{array}{c}87.41 \\
(4,298 / 4,917)\end{array}$ & $\begin{array}{c}38.54 \\
(765 / 1,985)\end{array}$ & $\begin{array}{c}34.51 \\
(471 / 1,365)\end{array}$ & $\begin{array}{c}32.42 \\
(700 / 2,159)\end{array}$ & $\begin{array}{c}25.40 \\
(1,273 / 5,012)\end{array}$ & $\begin{array}{c}21.99 \\
(248 / 1,128)\end{array}$ \\
\hline $\begin{array}{l}\text { Medical insurance payment } \\
\text { ratio (\%) }\end{array}$ & 88.06 & 103.28 & 108.48 & 107.78 & 114.79 & 103.74 \\
\hline $\begin{array}{l}\text { Balance from medical } \\
\text { insurance (Yuan) }\end{array}$ & $-1,036.23$ & 206.81 & 675.37 & 767.20 & $1,327.68$ & 287.61 \\
\hline
\end{tabular}

DRGs, diagnosis-related groups; DM, diabetes mellitus.

system is that medical insurance pays patients in DRGs according to their disease type, severity, treatment, and other conditions $(5,7,15,16)$. Since 2019 , the hospital has simulated payment based on DRGs. After 2 years of preparation, we implemented the DRGs payment assessment in the endocrinology department in 2021. Following a 6-month effort, the application of the DRGs tool has achieved initial results that the development model of the endocrinology department is changed from extensive development to the in-depth development, focusing on the specialized diagnosis/treatment capacity and medical quality.

In the first half of 2021, compared with the same period in 2019, the economic data quality of endocrinology department improved significantly, and the cost structure was more reasonable. The proportion of pharmaceutical expenses decreased by $17.47 \%$, and the proportion of medical service income increased by $16.93 \%$. The CEI and TEI decreased markedly, and the average hospitalization cost and average length of stay also decreased significantly. The number of people discharged from hospitals dropped by $8.86 \%$. The endocrinology department focuses on the construction of disciplinary connotation, and has improved the medical quality by developing sub-specialties, actively carrying out new diagnosis and treatment projects (such as interventional surgery), carrying out blood glucose management across departments, and implementing clinical pathways. Diseases groups are more widely distributed, and the clinical services are more in line with the orientation of the endocrinology specialty in 3a hospitals. In the first half of 2021, the number of DRGs groups increased from 162 to 176 , and the proportion of clinical pathways increased from $77.76 \%$ to $86.64 \%$ compared with the same period in 2019. Under the new situation, to promote the high- quality development of the endocrinology department in $3 \mathrm{a}$ hospitals, the following three new ways are worth exploring.

\section{Use diabetes big data and informatization to carry out blood glucose management in the whole hospital}

According to statistics, about $50 \%$ of patients with diabetes will undergo at least one operation in their lifetime for various reasons, and the incidence of surgical mortality and postoperative complications in patients with diabetes is five times higher than that in non-diabetic patients $(17,18)$. In the hospital, $71.58 \%$ of inpatients with diabetes were in a non-endocrinology department. Therefore, the quality of diagnosis and treatment of diabetes patients can be significantly improved by enhancing the management of blood glucose in the hospital, especially the management of diabetes patients in the surgical department.

Comprehensive analysis has shown that the proportion of inpatients with diabetes in the hospital was more than $20 \%$ and the proportion of medical insurance payment was more than $100 \%$, including in the rehabilitation, neurology, nephropathy, ophthalmology, and general departments. Therefore, the endocrinology department is the first choice to cooperate with these five departments for blood glucose management, which can make full use of medical insurance funds and human resources of the professional medical team of the endocrinology department, complementing each other's advantages and improving the quality of blood glucose management of inpatients with diabetes in the hospital. At the same time, the application of diabetes big data and information means to cross-department blood glucose management can promote the efficiency and level of blood glucose management in the whole hospital. 


\section{Promote the development of sub-specialties}

The CMI values of diabetes and related diseases are lower than those of other endocrine diseases $(18,19)$. Therefore, the new DRGs payment strategy also indirectly promoted the construction of endocrine sub-specialty. In May 2021, the endocrinology department of our hospital established four sub-specialties to promote the growth of sub-specialties via the centralized treatment of patients with sub-specialty diseases. In August 2021, the admission rate of patients with non-diabetic sub-specialty diseases in the endocrinology department increased to $95.12 \%$. The number of DRGs, time, and CEI of the department's medical quality data were significantly improved. Also, the improvement of the diagnosis/treatment capacity and quality of the endocrinology department promoted by the construction of sub-specialties has achieved rapid results, which is consistent with the original intention of the DRGs payment policy to reduce fees and increase efficiency.

In addition, the prognosis of patients with diabetic foot ulcer has been improved by the treatment of multidisciplinary team (MDT) in some domestic units $(11,13,20)$. The diabetes and complications sub-department of endocrinology in the hospital established MDT for diabetic wound diagnosis and treatment with orthopedics, plastic surgery, and vascular surgery, providing a 'one-stop' expert team diagnosis and treatment service for patients with diabetic foot ulcer, helping to build the sub-specialty of endocrinology department and improving the ability of the endocrinology department to lead fourth-level surgery. The implementation of centralized treatment for patients with sub-specialized diseases is only the first step in the establishment of sub-specialized diseases. Follow-up measures in personnel training, equipment acquisition, and the cultivation of new technologies for the diagnosis and treatment of special diseases are also needed, in order to continuously promote the development of sub-specialized diseases.

\section{Actively carry out interventional surgery and other diagnosis and treatment projects}

'Surgical internal medicine, minimally invasive surgery' is the current trend in the development of various specialties $(11,12,20,21)$. The new DRGs payment policy also promoted the continuous improvement of the surgical ability of the endocrinology department of our hospital. In the diagnosis and treatment of diabetic foot ulcer, wound regeneration and repair, and diagnosis of endocrine gland diseases, the interventional surgery and wound treatment operations participated in by endocrinologists are increasing every day, thereby guiding the continuous high-quality development of the endocrinology department $(11,13,14)$. In the first half of 2021, compared with the same period in 2019 , the number of surgical cases increased by $60.50 \%$, minimally invasive surgery increased by $53.54 \%$, grade 4 surgery increased by $66.67 \%$, and the mean CMI increased from 0.80 to 0.84 .

The practice of the endocrinology department in the hospital has demonstrated that the application of the DRGs tool can promote the diagnosis/treatment ability and medical quality of the endocrinology department, carry out blood glucose management in the whole hospital, build sub-specialties, and improve the surgical ability, which are effective ways to promote the development of the endocrinology department under the new policy.

To improve the clinical ability with DRGs tools in different departments, it is strongly recommended to evaluate DRGs payment data and clinical ability of the department at first. With these values, we can find the way to elevate CMI easier, for example building sub-specialties, treating patients with new techniques.

\section{Acknowledgments}

The authors thank the support from Wuhan Municipal Health Youth Talent Training Program.

Funding: This research received support from the Major Clinical Research Project of Wuhan Municipal Health Commission (No. WG20M01) and Hubei Provincial Health and Family Planning Scientific Research Project (No. WJ2017F017).

\section{Footnote}

Data Sharing Statement: Available at https://atm.amegroups. com/article/view/10.21037/atm-22-147/dss

Conflicts of Interest: All authors have completed the ICMJE uniform disclosure form (available at https://atm. amegroups.com/article/view/10.21037/atm-22-147/coif). The authors have no conflicts of interest to declare.

Ethical Statement: The authors are accountable for all aspects of the work in ensuring that questions related 
to the accuracy or integrity of any part of the work are appropriately investigated and resolved.

Open Access Statement: This is an Open Access article distributed in accordance with the Creative Commons Attribution-NonCommercial-NoDerivs 4.0 International License (CC BY-NC-ND 4.0), which permits the noncommercial replication and distribution of the article with the strict proviso that no changes or edits are made and the original work is properly cited (including links to both the formal publication through the relevant DOI and the license). See: https://creativecommons.org/licenses/by-nc-nd/4.0/.

\section{References}

1. Feng L, Tian Y, He M, et al. Impact of DRGs-based inpatient service management on the performance of regional inpatient services in Shanghai, China: an interrupted time series study, 2013-2019. BMC Health Serv Res 2020;20:942.

2. Kutz A, Gut L, Ebrahimi F, et al. Association of the Swiss Diagnosis-Related Group Reimbursement System With Length of Stay, Mortality, and Readmission Rates in Hospitalized Adult Patients. JAMA Netw Open 2019;2:e188332.

3. Yip W, Fu H, Chen AT, et al. 10 years of health-care reform in China: progress and gaps in Universal Health Coverage. Lancet 2019;394:1192-204.

4. Papanicolas I, Woskie LR, Jha AK. Health Care Spending in the United States and Other High-Income Countries. JAMA 2018;319:1024-39.

5. Zou K, Li HY, Zhou D, et al. The effects of diagnosisrelated groups payment on hospital healthcare in China: a systematic review. BMC Health Serv Res 2020;20:112.

6. National Health Insurance Administration, Ministry of Finance, National Health Commission, National Administration of Traditional Chinese Medicine. Circular on the publication of a list of national pilot cities that pay according to diagnosis-related groups. 2019. Available online: http://www.nhsa.gov.cn/art/2019/6/5/ art_37_1362.html

7. Office of National Healthcare Security Administration. Notification of the publication of paid national pilot technical specifications and cluster programmes for diagnosis-related groups (DRGS). 2019. Available online: http://www.nhsa.gov.cn/art/2019/10/24/art_37_1878.html

8. Office of National Healthcare Security Administration. Notice on the issuance of the Medicare diagnosis- related groups (CHS-DRG) subcluster Program (version 1.0). 2020. Available online: http://www.nhsa.gov.cn/ art/2020/6/18/art_37_3240.html

9. Han CY, Li C, Chen HL, et al. Establishment of Evaluation Index System of Specialized Clinical Capacity Based on C- DRG. Chinese Health Economics 2020;39:36-8.

10. Liu R, Shi J, Yang B, et al. Charting a path forward: policy analysis of China's evolved DRG-based hospital payment system. Int Health 2017;9:317-24.

11. Neupane S, Edla S, Maidona E, et al. Long-term outcomes of patients with diabetes mellitus undergoing percutaneous intervention for popliteal and infrapopliteal peripheral arterial disease. Catheter Cardiovasc Interv 2018;92:117-23.

12. Yammine K, Otayek J, Assi C. Evidence-based conservative limb preserving surgery for the diabetic foot complications: A systematic review of systematic reviews. Foot Ankle Surg 2021. [Epub ahead of print]. doi: 10.1016/j.fas.2021.08.006.

13. Chinese Diabetes Soiety; Chinese Society of Infectious Diseases; Chinese Society for Tissue Repair and Regeneration. Chinese guideline on prevention and management of diabetic foot (2019 edition) (II). Chinese Journal of Diabetes Mellitus 2019;11:161-89.

14. Qu W, Wang Z, Hunt C, et al. The Effectiveness and Safety of Platelet-Rich Plasma for Chronic Wounds: A Systematic Review and Meta-analysis. Mayo Clin Proc 2021;96:2407-17.

15. Xu J, Jian $W$, Zhu K, et al. Reforming public hospital financing in China: progress and challenges. BMJ 2019;365:14015.

16. Chu Y, Tao H. Detecting Undifferentiation of Tertiary and County Hospitals in China in Adoption of DRG Instrument. Healthcare (Basel) 2021;9:922.

17. Gao J, Lou XE, Zhang LP, et al. Comparison between insulin pump or multiple subcutaneous insulin injection therapy on perioperative diabetes patients. Chinese Journal of Diabetes 2013;21:807-10.

18. Albu JB, Sohler N, Li R, et al. An Interrupted Time Series Analysis to Determine the Effect of an Electronic Health Record-Based Intervention on Appropriate Screening for Type 2 Diabetes in Urban Primary Care Clinics in New York City. Diabetes Care 2017;40:1058-64.

19. Ji X, Fang Y, Liu J. Performance assessment of the inpatient medical services of a clinical subspecialty: A case study with risk adjustment based on diagnosisrelated groups in China. Medicine (Baltimore) 
2018;97:e10855.

20. Rayman G, Vas P, Dhatariya K, et al. Guidelines on use of interventions to enhance healing of chronic foot ulcers in diabetes (IWGDF 2019 update). Diabetes Metab Res Rev 2020;36 Suppl 1:e3283.

Cite this article as: Ding S, Jiang X, Zheng Y, Feng T, Mao H, Chen Z, Cai W, Wang Z. Improving the clinical ability and quality of endocrinology department with diagnosis-related groups tool. Ann Transl Med 2022;10(4):167. doi: 10.21037/ atm-22-147
21. Farber A. Chronic Limb-Threatening Ischemia. N Engl J Med 2018;379:171-80.

(English Language Editor: A. Kassem) 